\title{
Pop-up satellite archival tag (PSAT) temporal data resolution affects interpretations of spawning behaviour of a commercially important teleost
}

\author{
Jonathan A. D. Fisher ${ }^{1 *}$, Dominique Robert ${ }^{1,3}$, Arnault Le Bris $^{1}$ and Timothy Loher ${ }^{2}$
}

\begin{abstract}
Background: The effects of temporal data resolution on the interpretation of fish behaviours are questions fundamental to research programs using electronic tags with finite data storage and data transmission capacities. However, understanding these effects requires sub-sampling high-resolution data at multiple temporal resolutions. In pop-up satellite archival tags (PSATs), data transmissions via satellite are limited, so temporal resolution is a decreasing function of the deployment duration. Physical recovery of PSATs overcomes this limitation, providing data on temperature, depth, etc., at rates at least 15-30 times greater than transmitted data.

Results: Using PSATs physically recovered from Atlantic halibut (Hippoglossus hippoglossus), we evaluated the effects of data resolution (2, 30,60 min) on interpreting vertical movements including rapid ascents during the expected spawning season. Putative 'spawning rises' of 6-20 min were only present within highest temporal resolution data. Vertical movement rates during spawning rises identified with high-resolution data exceeded rates in all other periods; such movement rates were virtually absent in all other tagged fish within the spawning period. Mean maximum ascent rates were 13 and 23 times higher when the sampling interval was 2 versus 30 or 60 min, respectively.

Conclusions: We illustrate the limitations of using satellite-transmitted data to quantify vertical movement rates and detect potential spawning events in marine teleosts. Such low temporal resolution data suggest spurious results by masking important behaviours that archived data reveal as occurring at high frequencies. We highlight new technologies that facilitate PSAT recoveries at sea to overcome these limitations and facilitate analyses of high-frequency archived data.
\end{abstract}

Keywords: Atlantic halibut, Goniometer, PSAT recovery, Sampling interval, Spawning rise, Time series

\section{Background}

The increasing application of pop-up satellite archival tags (PSATs) to questions in marine research has expanded from a focus largely on large pelagic species [1-3] to include large flatfishes, including Pacific halibut (Hippoglossus stenolepis) [4-7], Greenland halibut (Reinhardtius hippoglossoides) [8], and Atlantic halibut

\footnotetext{
${ }^{*}$ Correspondence: jonathan.fisher@mi.mun.ca

${ }^{1}$ Centre for Fisheries Ecosystems Research, Fisheries and Marine Institute, Memorial University of Newfoundland, PO Box 4920, St. John's, NL A1C 5R3, Canada

Full list of author information is available at the end of the article
}

(Hippoglossus hippoglossus) [9, 10]. A recognized advantage of PSATs is their ability to collect data on temperature, depth, and light levels and then transmit those data directly through the Argos satellite system [11] following their programmed release and emergence at the water's surface. These features negate the need to recover the tag to obtain data. PSAT technologies continue to improve, partly through users' quantification of their benefits and limitations [2,12-14] and communication between researchers and PSAT manufacturers [14, 15]. However, given finite memory, limited battery capacities and restricted transmission capabilities, there often 
remain inherent trade-offs between deployment duration and the proportions of recorded data that are transmitted and received through satellite systems $[13,16]$ but see [17]. As in large pelagic species, an increasing number of questions on large flatfishes involve pelagic habitat use [18] and migrations over an annual cycle [19]. It is therefore necessary to quantify how such trade-offs influence interpretations of marine fish behaviour in order to optimize PSAT deployments and data analyses.

Conceptually, the limitations of temporal data resolution on signal detection have long been described within the context of the 'sampling theorem' developed within communications science [20]. That theorem can be paraphrased as: detecting a signal is limited to situations where the sampling frequency is at least twice the signal frequency. At lower sampling frequencies, aliasing becomes a problem in which processes occurring at high frequencies cannot be resolved; the effects of aliasing are especially important for interpreting cyclical processes. Due to these factors, data temporal resolution strongly influences interpretations of animal movements, with lower sampling frequencies observed [16, 21] and expected $[22,23]$ to underestimate movement rates. Empirically, data temporal resolution has been reported to restrict estimates of vertical movement rates in billfishes [24] and demersal fishes [21], affect interpretations of vertical habitat use by sailfish [25], limit the detection of irregular post-release behaviours in large pelagic fishes [26], and constrain analyses of periodic vertical movement in coastal striped bass [27].

An additional, important behavioural inference that may be affected by PSAT data temporal resolution is spawning behaviour. Data resolution has been reported to affect the capacity to detect specific behaviours indicative of spawning in Atlantic Bluefin tuna [28]. Previous authors studying the movements and behaviours of Pacific halibut reported probable 'spawning rises' based on data archived at 1-min intervals within PSATs that were either recovered in the fishery still attached to halibut [4] or detached from halibut and washed up on Alaskan beaches [7]. While direct evidence of spawning may not be derived from PSAT data alone, both the observations of such rapid, transient vertical movements associated with spawning within at least seven flatfishes, and the repeated and protracted nature of the rises with lags associated with the ovulation intervals of repeated spawning by female Atlantic halibut [29], provided support for this hypothesis in Pacific halibut [4]. However, aside from such analyses performed on high-resolution (defined as $\leq 2$-min resolution) data from recovered PSATs, and presumed spawning rises based on PSAT data reported at 6-h intervals [9], an evaluation of the effects of data temporal resolution from PSATs on the interpretation of such short-term behaviours has not yet been undertaken on Atlantic halibut. Such an analysis is required to determine the minimum temporal resolution of transmitted data required to identify spawning rise events.

In order to analyse the effects of PSAT temporal data resolution on interpretations of vertical movements and spawning rises, we focus on the Atlantic halibut population within the Gulf of St. Lawrence that supports fisheries within five Canadian provinces (Fig. 1). Landings in this fishery were as high in 2014-2015 as at any time in the past 50 years, despite the fishery being managed by precautionary total allowable catches (TACs) and other restrictions [30]. Since a TAC of $300 \mathrm{t}$ was first established in 1988, TACs have more than tripled [31]; quota for 2015 was set at $1036.8 \mathrm{t}$.

Identifying spawning behaviour is a key precursor to quantify spawning times and locations. Many spawning locations are known for Pacific halibut $[32,33]$ and have been elucidated based on PSAT data for both Pacific halibut [5, 34] and Northeast Atlantic halibut [10] populations. However, such critical population information is currently acknowledged as lacking in the two Northwest Atlantic halibut stocks that support combined landed values in excess of $\$ 38$ million CDN annually $[9,31]$. This is due to an absence of information on spawning behaviour, timing and location. When spawning behaviour is accurately characterized and combined with modelling approaches that reconstruct movements over an annual cycle based on PSAT-recorded temperature and depth, and an understanding of the local temperature fields and bathymetry [35], high-resolution data recovered from

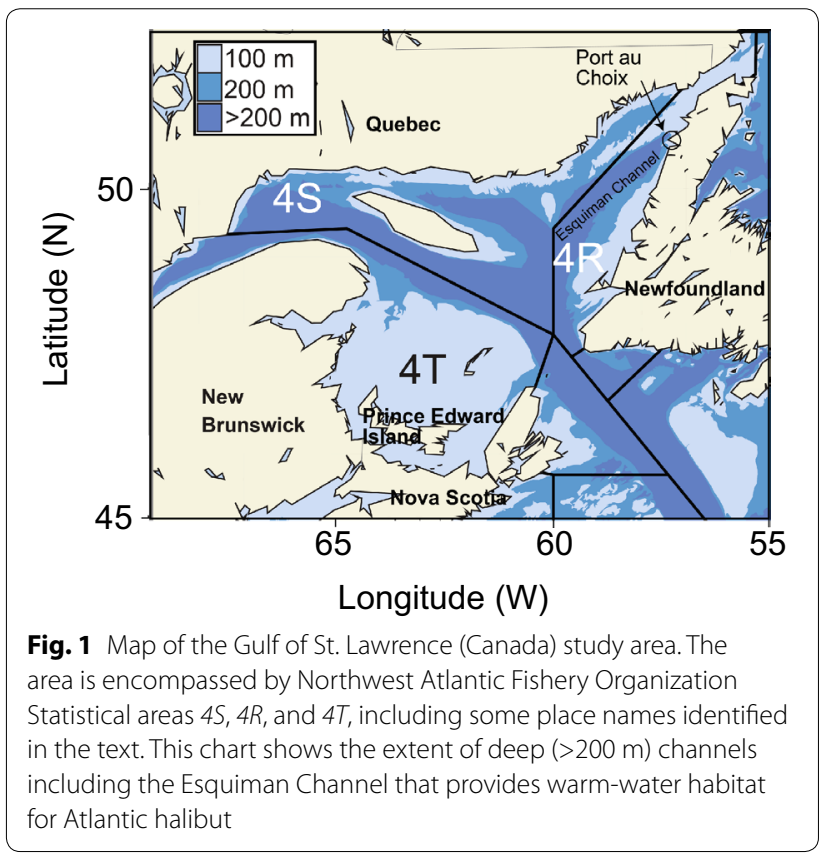


PSATs provide new opportunities to identify spawning locations of Atlantic halibut in the Gulf of St. Lawrence [36].

Here, we first report on the application of new technologies to assist in the physical recapture of detached and floating PSATs. We then evaluate the effects of data resolution, using PSATs sampling at three temporal resolutions, on interpretations of vertical movement behaviours of Atlantic halibut, with a focus on putative spawning rises. While the results related to the timing and duration of spawning events are specific to this population, the concepts and caveats about interpretations of electronic tagging data are general and may be used in the design of other tagging programs and the interpretation of resulting electronic tagging data.

\section{Methods}

PSATs were deployed in October 2013 within a combined conventional tagging and satellite tagging program to provide new information on the distributions, growth and recapture rates, and movements of the mature component of the Atlantic halibut stock within the Gulf of St. Lawrence, Canada. In total, twenty halibut $>100 \mathrm{~cm}$ fork length caught by longliners off of Port au Choix, Newfoundland (50.596 N, 57.559 ${ }^{\circ}$ W; Fig. 1), were tagged with PSAT 'Standard Rate X-Tags' from Microwave Telemetry, Inc., Columbia, Maryland, USA (hereafter abbreviated as 'X-Tags', 'MTI'). Tagging was undertaken under Fisheries and Oceans Canada Experimental License NL-2082-13 and Memorial University Animal Care Protocol 13-01-DR. Fourteen PSATs were programmed to record temperature, light, and depth (pressure) data for a period of 1 year before detaching from halibut; these tags formed the basis of the subset of recovered tags analysed here. The remaining 6 PSATs were programmed to release after 3- or 6-month duration and are not considered within this study. PSATs were attached to the eyed side of halibut at the dorsal fin using a titanium dart and monofilament tether anchored through the pterygiophores, using a procedure that has been experimentally shown to yield survival rates indistinguishable from untagged Pacific halibut held in captivity over a period of $>248$ weeks [37].

X-Tags recorded temperature, pressure (depth), and light measurements every $2 \mathrm{~min}$, while the tag was in data collection mode. The tag stored this entire time series 'archived' dataset in memory; archived data were not binned or averaged. If an X-tag is physically recovered, the archived dataset may be extracted covering the full duration of deployment. However, the entire archived dataset cannot be transmitted due to limited battery life and Argos system data throughput limitations. Given these constraints, a subset of data is selected by the tag's program for transmission; this constitutes the 'transmitted' dataset.

Transmitted datasets are generated from a sequence of compressions and calculations applied to the archived dataset; these calculations cannot be reprogrammed in the field. This dataset still contains depth and temperature time series but with decreased temporal and measurement resolution. The temporal resolution of the transmitted dataset depends on the length of deployment [13]; the temporal resolution declines as the deployment progresses. If an X-tag is deployed for a short period of time $(<4$ months), the temporal resolution is $15 \mathrm{~min}$. As the X-tag deployment continues (4-8 months), the 15-min records are overwritten with 30-min records. Similarly, as X-tag deployment continues past 8 months, the 30 -min records are overwritten with hourly records. Although the temporal resolution may vary throughout deployment, it is constant over the course of each day.

Even if a PSAT transmits $100 \%$ of the transmitted dataset, not all of the data may be received by the Argos system [13]. The dataset that is successfully transmitted through the Argos system is referred to as the 'received' dataset. The temporal resolution of the received dataset depends on deployment duration and the percentage of data received through the Argos system.

Given that a goal of our analyses was to examine best-case scenarios of data storage and transmission, we focus exclusively on the archived and transmitted datasets derived from six PSATs that were deployed for a year and physically recovered (Table 1 ). Tag recovery at sea was facilitated through the use of a CLS RGX-134 digital receiver with RG-58 direction finding antenna (CLS America Inc., Lanham, Maryland, USA) (Fig. 2). Together, this CLS 'goniometer' (from the Latin 'angle-meter') provided a device capable of receiving Argos pings emanating from PSAT data transmissions $(401.650 \mathrm{MHz})$ once each minute. The goniometer indicated both the direction of the Argos ping relative to a forward-facing antenna and a measure of relative signal strength so that tags floating at the surface could be tracked, visually identified and recovered at sea. Recovery was performed aboard the 45 foot longline vessel $J$ Elizabeth and facilitated by calm seas. The RXG 58 antenna was mounted on the wheelhouse about $4.5 \mathrm{~m}$ above the water's surface, and the receiver was placed beside the captain. The vessel steamed in the direction of the tag. When the intensity of the signal increased, the vessel slowed, and when the angle to the tag became large, each floating PSAT was observed alongside the vessel and collected with a net. Floating PSAT transmission durations spanned approximately 2 weeks, providing a relatively wide temporal window for recovery. 
Table 1 Identifications, deployment dates and times, dates and times when the tags reached the surface ('Pop-up date/ time') for the six PSATs that were physically recovered following deployment on Atlantic halibut

\begin{tabular}{|c|c|c|c|c|c|c|c|c|}
\hline Tag ID & $\begin{array}{l}\text { Halibut length } \\
\text { (cm) }\end{array}$ & $\begin{array}{l}\text { Deployment } \\
\text { date }\end{array}$ & $\begin{array}{l}\text { Deployment } \\
\text { time }\end{array}$ & $\begin{array}{l}\text { Programed } \\
\text { pop-up date }\end{array}$ & $\begin{array}{l}\text { Actual pop-up } \\
\text { date }\end{array}$ & Pop-up time & $\begin{array}{l}\text { Number } \\
\text { of archived } \\
\text { data }\end{array}$ & $\begin{array}{l}\text { Number } \\
\text { of transmitted } \\
\text { data }\end{array}$ \\
\hline 131931 & 108 & Oct/1/2013 & $17: 24$ & Oct/1/2014 & Oct/1/2014 & $14: 16$ & 262582 & 11788 \\
\hline 131927 & 125 & Oct/1/2013 & $20: 19^{a}$ & Oct/1//2014 & Oct/6/2014 & $10: 21$ & 269993 & 11923 \\
\hline 131926 & 139 & Oct/2/2013 & $11: 30$ & Oct/2/2014 & Oct/2/2014 & $8: 33$ & 263382 & 11818 \\
\hline 131924 & 125 & Oct/1/2013 & $20: 04^{\mathrm{a}}$ & Oct/1/2014 & Oct/1/2014 & $17: 02$ & 262214 & 11810 \\
\hline 131920 & 126 & Oct/1/2013 & $20: 16^{\mathrm{a}}$ & Oct/1/2014 & Oct/1/2014 & 19:56 & 264019 & 11836 \\
\hline 131932 & 140 & Oct/1/2013 & $20: 19^{a}$ & Oct/1/2014 & $\mathrm{Jul} / 24 / 2014$ & $20: 00$ & 212920 & 11669 \\
\hline
\end{tabular}

Also listed are the total numbers of 'archived' data (2-min resolution) and 'transmitted' data (30- or 60-min resolution) between the identified dates and times

a Indicates a minimum deployment time, as there were no data recovered that registered surface depths on the deployment date. PSAT 131932 was recovered in the halibut fishery, attached to the halibut
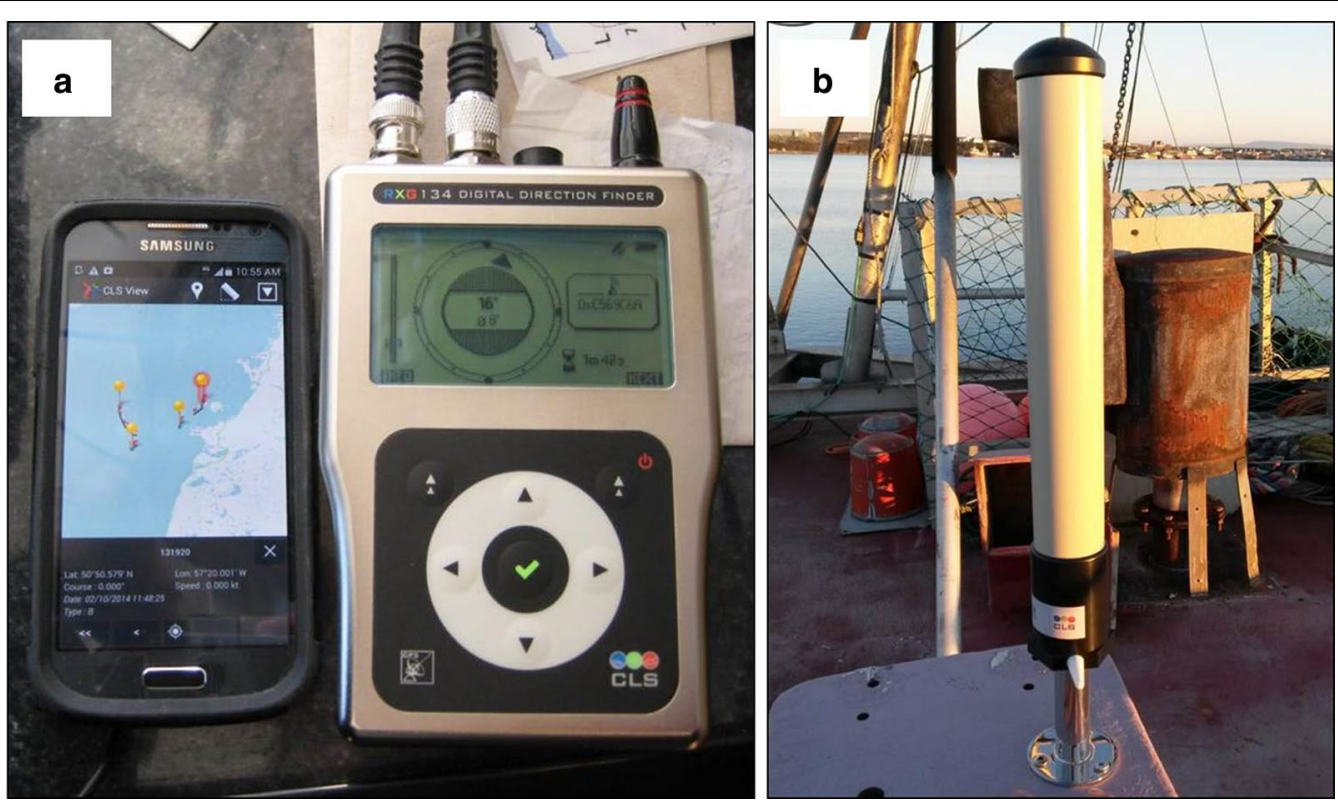

Fig. 2 Equipment used to recover PSAT tags. a Illustration of the CLS View Android application running on a cell phone and showing the locations of four PSATs floating at the surface (left) beside the CLS RXG135 receiver (right). b The RG58 directional antenna mounted above the bridge of the 45 -foot longliner J Elizabeth. The white protruding cone above the silver base plate is the 0 -degree reference for all angles. In combination, these products facilitated the rapid recovery of five PSATs at sea and subsequent analyses of the effects of temporal resolution on the detection and quantification of rapid, episodic vertical fish movements

Recovered tags were shipped to MTI where technicians extracted both the archived data series (recorded at a constant resolution of every $2 \mathrm{~min}$ ) and the transmitted data series (those data recorded at resolutions of 30 or $60 \mathrm{~min}$ ) that were based on sequential overwriting of higher-resolution data as deployment durations persisted. Because they were retrieved from the memory of physically recovered tags, transmitted data series represented a continuous, best-case time series of data that theoretically could have been received by the satellite (Fig. 3).
Analyses of vertical distributions and potential spawning rises were undertaken using visual comparisons of the full archived and transmitted time series (following [4]). Spawning rises were defined as series of abrupt ascents, generally $25-100 \mathrm{~m}$ in magnitude, with a pronounced and very brief (i.e. 'pointed') apex, each of which was $\sim 10 \mathrm{~min}$ in duration, and conducted during mid-winter. In order to examine the abruptness of ascents (and descents), using archived data we calculated the first-order differences in rate of depth change for all events during the January-May spawning period. 


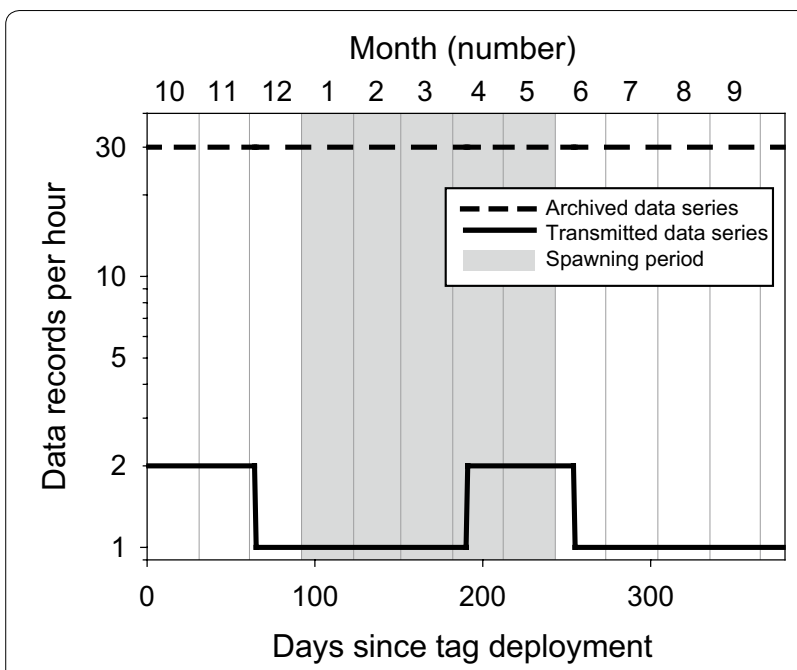

Fig. 3 An overview of the temporal resolutions of archived and transmitted data series. Both are functions of sampling date since PSATs were deployed in October 2013, for PSATs recording data for a full year. The change in temporal resolution in the transmitted series is due to overwriting higher-frequency data as the sampling duration increases, as part of the algorithm for data storage within Microwave Telemetry Incorporated X-Tags. The expected spawning period for Atlantic halibut in the Gulf of St. Lawrence, occurring during months $1-5$, is also highlighted by the shading

After excluding zero values, we explored whether 'spawning rise' events, as evident in frequency distributions of ascent or descent rates from a putative spawning fish (PSAT 131932), were also characterized by more abrupt changes in depths that were not evident in other periods or other PSAT records. To do this, we generated the same first-order differences from all PSATs in order to compare their maximum rates of ascent/descent with PSAT 131932. Finally, mean maximum rates of halibut vertical ascents were calculated for each fish tagged by taking the mean of the greatest vertical movement per day based on adjacent records and calculating ascent rates per minute [21]. These analyses were undertaken within the period of 4-13 April 2014; an arbitrary time period, but one that spanned both the 30-min and 60-min transmitted data sampling intervals (Fig. 3) such that ascent rates based on archived data (2-min sampling intervals) could be compared against ascent rates based on the transmitted data that were collected at the two different rates, all within consecutive 5-day periods. To test for potential differences in ascent rates as a function of temporal data resolution, we compared the observed $t$ values between $n=25$ (individuals by day) data at two temporal resolutions against the distributions of $9999 t$ values based on randomizations of the ascent rate data. The null hypothesis of no difference between observed $t$ value and randomized $t$ values was tested using a one-sided test, where the alternative hypothesis was that higher temporal resolution would have higher ascent rates.

\section{Results}

Of the fourteen PSATs deployed for a year, one surfaced in December 2013 and transmitted data; another was recovered in the fishery on 24 July 2014 and returned to the investigators. Of the remaining twelve tags, eight surfaced and transmitted data in early October 2014, on or within 4 days of the programmed release date; five of these were recovered within range of Port au Choix, NL using the goniometer (Table 1). During PSAT recoveries at sea, the CLS View Android application (Fig. 2) provided the tags' last known positions. Argos signals were detected by the goniometer within approximately $3.6 \mathrm{~km}$ of the emitting PSATs. Among the five tags recovered with the goniometer, the average search time once a tag was detected was $44 \mathrm{~min}$ (range $20-98 \mathrm{~min}$ ).

In all six of the recovered tags, the archived 2-min data series was accompanied by the transmitted series at temporal resolutions of 30 or $60 \mathrm{~min}$. In comparisons of numbers of data points that were generated, transmitted data on average represented $4.6 \%$ of the total archived data (Table 1). Generally, both series recorded that halibut remained at deep locations throughout the winter and spring in habitat that displayed relatively stable water temperatures $\left(\sim 5^{\circ} \mathrm{C}\right)$, before heading to shallower depths with much more variable temperatures $\left(0-15{ }^{\circ} \mathrm{C}\right.$ [36]) due, in part, to the presence of a cold intermediate layer of water [38]. Within the transmitted data series, the different temporal resolutions through the year illustrate the sections that were overwritten at the lowest resolution after a year's deployment and data collection (Fig. 3). It is notable that overwriting provided low resolution in the transmitted data series from January to early April (Fig. 3), which represents the majority of the expected halibut spawning period (January-May; [30]).

Within the expected spawning period of Atlantic halibut, two of six recovered tags showed evidence within their high-resolution depth data of the fish having conducted rapid ascents of $>20 \mathrm{~m}$, as occurred in early February in the X-tag 131932 (Fig. 4a) and throughout January and February in X-tag 131931 (Fig. 4c). In one fish, these putative spawning rises occurred six times in sequence, lasting between 4 and $20 \mathrm{~min}$, with ascents ranging from 25.2 to $80.4 \mathrm{~m}$ and initiated from depths that were always below $250 \mathrm{~m}$ (Fig. 4a). The average time between these events was $80.7 \mathrm{~h}$ and with a narrow range of 73.9-92.9 h, or every three to 4 days. These rises were present within examinations of changes in depth within archived data (see Additional files 1,2) but largely absent and represented by single points using lower-resolution data (Fig. 4b, d). X-tag 131931 exhibited a prolonged 

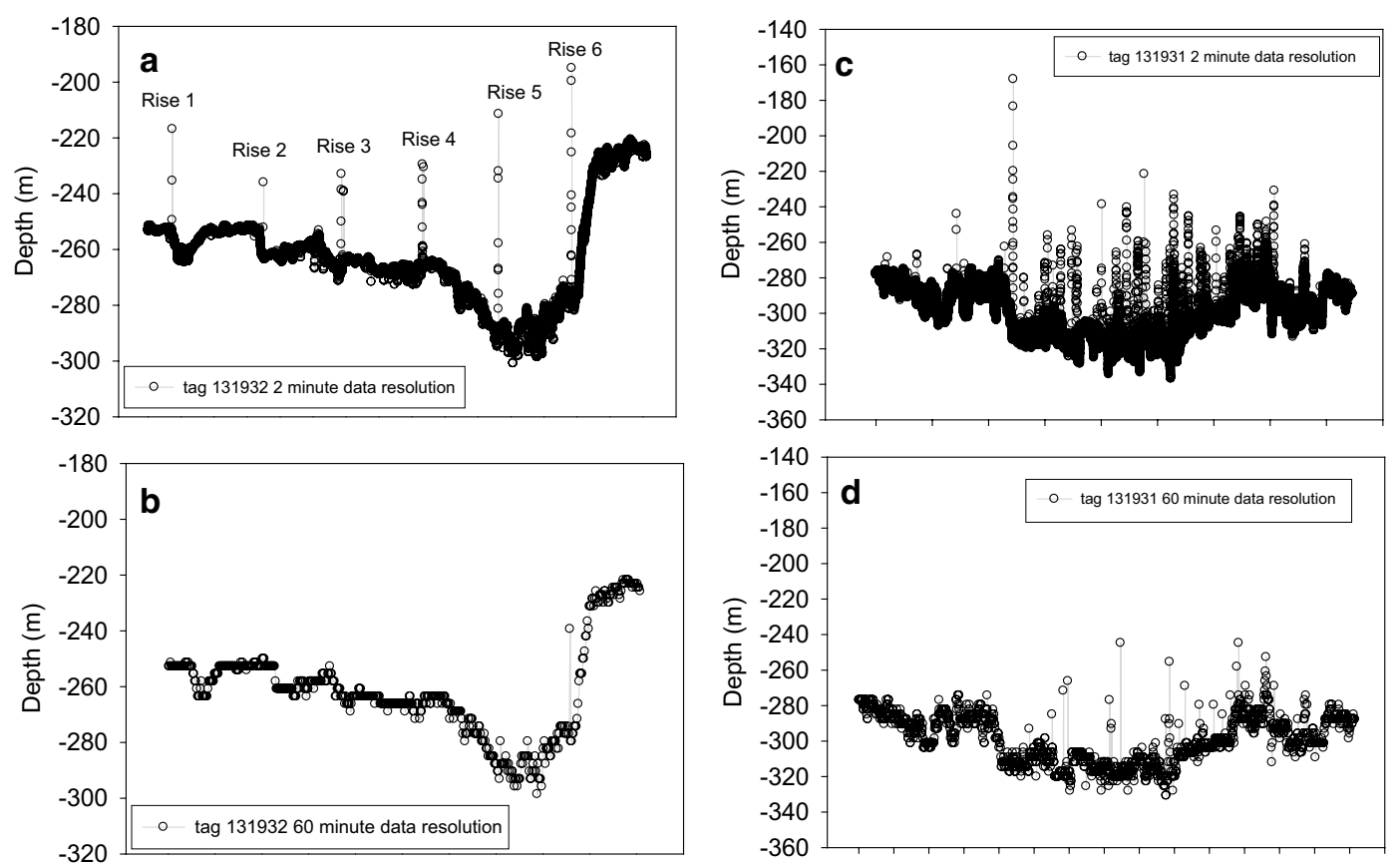

Fig. 4 The effects of data resolution on the detection and interpretation of putative spawning rises. Data are from two Atlantic halibut from recovered PSATs. a PSAT 131932 'Archived' data series from 8 February 2014 to 1 March 2014 at a 2-min data resolution. b PSAT 131932 'Transmitted' data series from 8 February 2014 to 1 March 2014 at a 60-min temporal resolution. c PSAT 131931 'Archived' data series from 1 January 2014 to 28 February 2014 at a 2-min data resolution. d PSAT 131931 'Transmitted' data series from 1 January 2014 to 28 February 2014 at a 60-min temporal resolution. Note that most of the rapid ascents and descents (on the order of 6-20 min) in $\mathbf{a}, \mathbf{c}$ are absent from the transmitted data series $\mathbf{b}$, $\mathbf{d}$

period of high-frequency vertical ascents and descents that differed from 131932 (Fig. 4c). Similarly to the other tag, however, the vertical extent and frequency of these events were under-represented in the transmitted data series and most of the events that were recorded in the longer-period time series were characterized by a single point (Fig. 4d).

Rates of change in depth from the archived data illustrate clear differences in movement rates during apparent spawning rises compared to all other movements during the potential spawning period. For example, of $n=29,441$ changes in depth recorded by PSAT 131932 , very few illustrate ascents $>11.4 \mathrm{~m}(n=19)$ and descents $>9.1 \mathrm{~m}(n=14)$ within 2 -min intervals (Additional file 1$)$, rates that were only observed during the six putative spawning rises identified in Fig. 4a. Notably, all six putative spawning rises also had ascents and descents at these extremes of the frequency distribution, illustrating their potential utility to diagnose this unique behaviour. PSAT 131931-also identified as exhibiting potential spawning rises-was the only other tag to show such magnitudes of ascent/descent rates (Additional file 2). In comparison,

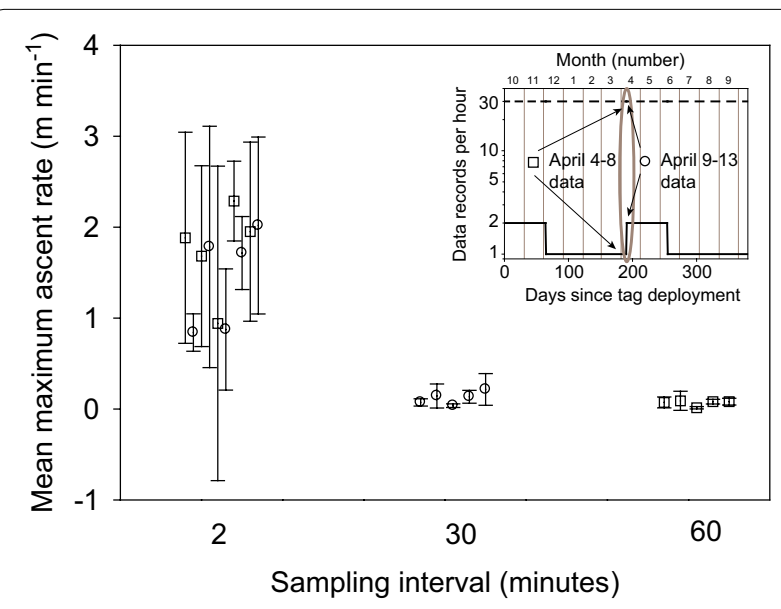

Fig. 5 The influence of sampling interval on daily maximum ascent rates. Plotted are mean maxima $( \pm S D)$ among five PSATs within two adjacent 5-day, arbitrarily chosen time periods when the 'transmitted' data series were resolved at sampling intervals of 60 min (4-8 April 2014; squares) and $30 \mathrm{~min}$ (9-13 April 2014; circles), as depicted in the inset figure. The repeated five points (at sampling intervals of 30 and $60 \mathrm{~min}$ ) or 10 points (2-min sampling interval) represent PSATs 131920-131931 listed in Table 1 and are offset to highlight differences among PSATs 
among the remaining 4 PSATS, only 4 out of $n=116,456$ first-order differences had changes in depth within these tails of the frequency distribution (Additional file 2).

Mean maximum ascent rates differed markedly as functions of sampling interval during the early April period examined. Compared to transmitted data series, archived data (average $1.60 \mathrm{~m} / \mathrm{min}$ ) yielded ascent rates 13 and 23 times higher than transmitted data sampled at intervals of $30 \mathrm{~min}$ (average $0.12 \mathrm{~m} / \mathrm{min}$ ) and $60 \mathrm{~min}$ (average $0.07 \mathrm{~m} / \mathrm{min}$ ), respectively (Fig. 5). In none of the 9999 randomizations did $t$ values exceed the observed $t$ values between 2 - versus 30 -min resolutions or between 2 - versus 60 -min resolutions. Comparing 30 - versus 60 -min temporal resolutions, in only 280/9999 randomization trials $(p=0.028)$ were the randomized $t$ values greater than the observed $t$ value.

\section{Discussion}

Using results from PSATs deployed on Atlantic halibut in the Gulf of St. Lawrence provides both a model system to illustrate how temporal data resolution can constrain the ability to address specific research questions and a case study in which new technologies to recover PSATs have helped to circumvent data transmission limitations and thereby provide new insights into fish behaviours based on high temporal data resolution.

Generally, data temporal resolution affects the identification of animal movements and quantification of their rates [16, 21-23]. This was the case with our tagging results, with higher temporal resolution data providing vertical movement rates that were inversely related to sampling frequencies and accounting for 13- or 23-fold differences in maximum ascent rates (Fig. 5). The same pattern of a strong effect of data recording frequency-and similar differences in magnitudes-was reported previously for Atlantic cod (Gadus morhua) within the Northeast Atlantic [21], which illustrates the generality of this issue in affecting the perceived movement rates of fishes.

Given their direct effect on estimated movement rates, temporal data resolution constrains the types of behavioural questions that can and have been asked of PSAT data. For example, in their review of PSAT deployments on large pelagic animals from a previous generation of tags (i.e. those produced between 2000 and 2004), Musyl et al. ([2]; their Table S2) reported that of 100 studies (and thereby accounting for $~ 50 \%$ of PSAT deployments), the data illustrate that globally, the vast majority $(90 \%)$ of studies of PSAT deployments on large pelagic species within their database had data resolutions of $1 \mathrm{~h}$ or more (Additional file 3). Therefore, interpretation of fish behaviours based on changes in temperature, depth, and light (including feeding, spawning, and thermal habitat use) and ultimately the framing of research questions based on satellite-derived PSAT data have been largely constrained to drivers and responses that act on periods longer than a couple of hours.

These constraints are evident across PSAT studies involving transmitted and archived data. For example, vertical movement rate estimates for Atlantic billfishes were limited to 6 recovered tags from which archived data were obtained [24]. Similarly, the quantification of periodicity in vertical movements in striped bass was constrained to three fish from which PSATs were physically recovered [27]. In addition to constraining sample sizes, PSAT archived data have indicated that irregular post-release behaviour in large pelagic fishes may go undetected using transmitted data [26], while PSAT archived data revealed more complex use of vertical habitat by sailfish than suggested by transmitted data [25] and high-frequency shallow oscillating dives characteristic of spawning in Atlantic Bluefin tuna [28]. These examples illustrate how the scope of research questions and the interpretation of key behaviours have been directly affected by the temporal resolution of PSAT data.

Within our study, even the best hypothetical case of continuously transmitted data series represented less than 5\% of the total archived data. Additionally, while we understood that transmitted data stored within the tag after 1 year would be recorded at temporal frequencies changing between 1 and 2 records per hour as a result of the data-overwriting algorithm within the tag, we had not anticipated that one prolonged period of lowest data resolution would happen to span much of the spawning period (Fig. 3). That result highlights the need for PSAT deployments to consider all aspects of the programming related to the timing and duration of deployments to maximize data recovery relative to the research questions $[13,15$, 16]. A key feature of the archived time series was its ability to resolve the timing, duration, and intervals separating rapid rises of two halibut (Fig. 4). This feature is probably one of the most reliable for ascertaining whether an ascent is likely to be spawning behaviour or some other vertical migration because it facilitates examination of rises for steepness and the shape of the peak (time at minimum depth) [7]; these features are key to interpretation of potential behaviours that were present within examinations of changes in depth within archived data (Additional files 1,2 ) but largely absent and represented by single points using lower-resolution data (Fig. 4b, d). Specifically, rates of change data support our contention that the spawning rise events are unique in their magnitudes of vertical change, as derived from 2-min resolution data.

Due to the inherent limitations of low temporal resolution PSAT data, the benefits of high temporal resolution data have also been highlighted by previous authors. For example, in addition to spawning rises in Pacific halibut 
$[4,7]$, data derived from physically recovered PSATs are generally examined separately from analyses of received data series, with archived data used to quantify vertical movement rates of billfishes [24, 39]. The archived data were better at revealing patterns of irregular post-release behaviour in large pelagic fishes than the satellite-derived data [35], and only archived data could identify highfrequency oscillating dives in Atlantic Bluefin tuna [28]. Archived data from PSAT-tagged Pacific halibut have recently been used to classify periodic behaviour and quantify the influences of biological and physical drivers [40].

The identification of apparent spawning rises is expected to contribute new information on the locations of halibut spawning within the Gulf of St. Lawrence. Previous characterizations of Canadian Atlantic halibut spawning behaviours and time periods have been derived from samples outside of the Gulf [41]; therefore, the identification of Gulf halibut spawning locations remains a research question of interest to Atlantic halibut assessment and management [31]. Our PSAT archived data are currently being investigated against seasonal bathymetric and temperature data to model the movements of Atlantic halibut within the Gulf of St. Lawrence over an annual cycle [36], using techniques first applied to Atlantic cod [35]. A necessary feature for modelling halibut movements over an annual cycle is continuous depth and temperature records, such that daily estimates of location can be estimated from prior location and seasonal hydrographic variables [38]. Combining the projections from that model with the detection of high-resolution 'spawning rises' during a brief period in the winter provides the first estimates of spawning locations for this stock [36].

Behaviourally, as in Pacific halibut [4], it is unclear whether the maximum extent of presumed spawning rises may be chosen to maximize dispersal of Atlantic halibut eggs. It is interesting to note, however, that the Gulf of St. Lawrence mixed layer depth in winter (March) averaged $75 \mathrm{~m}$ (28 m SD) [42], so that the apparent spawning rises would have released eggs below the mixed surface layer (Fig. 4). If this is indeed a behavioural trait of spawning halibut-and not simply an artefact of the rarity of recovered tags recording this behaviour-then it may constrain the spawning locations to those with mixed layer depths less than spawning rise depth. The mapped depths of the mixed layer for winter months [42] may permit testing this hypothesis in the future.

Although speculative, it is possible that some of the differences in vertical habitat use between fishes 131191 and 131192 (Fig. 4) are due to sex differences, with females (presumably fish 131192) necessarily waiting days between spawning events due to the energetic costs of hydrating eggs [29]. In contrast, if fish 131191 was male, the same energetic constraints may not limit spawning activity, such that higher frequency rises indicate spawning at will. This hypothesis can be tested in subsequent tagging missions using ultrasonic methods for determining sex developed for Atlantic halibut [43] and applied to Pacific halibut [44]. Potential sex differences may also be examined from these and subsequently tagged fish using fin-clip samples exposed to new genetic approaches [45].

The reliance of interpretations of high-frequency data from low numbers of physically recovered tags in this system has been somewhat circumvented through the use of the goniometer. The ability of the goniometer to facilitate PSAT recovery under appropriate sea conditions (i.e. winds $<15$ knots within a semi-enclosed Gulf) illustrates the utility of this method and contributes high temporal resolution data that will facilitate both comparisons with received data and movement modelling through analyses of continuous data time series.

\section{Conclusions}

Our study of Atlantic halibut illustrates the limitations of using satellite-transmitted data to quantify vertical movement rates and detect potential spawning events in marine teleosts. Such low temporal resolution data suggest spurious results by masking important behaviours that archived data reveal as occurring at high frequencies. We highlight new technologies that facilitate PSAT recoveries at sea to overcome these limitations and facilitate analyses of high-frequency archived data. This research adds new information, technology and techniques to the growing scientific bases that both highlight applications of telemetric research in aquatic systems [46, 47], and also the technical constraints on electronic tag data reporting [15], transmission to satellites $[13,16]$, and general performance related to deriving some data [2]. It has recently been stated that now is the golden age of animal-borne sensors due largely to technological innovations and their applications to ecological research [47]. Our research illustrates both the constraints inherent in electronic tagging data that are transmitted via satellite and the ability to circumvent those constraints using innovations to recapture tags at sea.

\section{Additional files}

Additional file 1. Boxplot (top panel) and frequency distribution (bottom panel) of first-order differences in depth from archived time series (i.e. 2-min temporal resolution; $n=29,441$ nonzero records) from PSAT 131932, a tag in which potential spawning rises were identified (Figs. 4, $5 a)$. While the vast majority of changes in depth were small, it is notable that all rises $>11.4 \mathrm{~m}(n=19)$ and all descents $>9.1 \mathrm{~m}(n=14)$ (both illustrated within the shaded boxes) occurred during the six spawning rises highlighted in Fig. 5 and all six periods had ascent/descent values 
at these extremes of the distribution. In comparison, the maximum first-order differences in depth from the four PSATs that did not show evidence of spawning rises from archived data $(131920,131924,131926$, 131927) had a total of four ascents $>11.4 \mathrm{~m}$, out of $n=116,457$ possible comparisons. These patterns illustrate that such magnitudes of depth changes are exceptionally rare outside of apparent spawning events (see also Additional file 2).

Additional file 2. Illustrations of the first-order differences in depth from archived PSAT data for all vertical movements between January 1 and May 31 for all 6 PSATs. In panels a-d, only 4 rises (of 116,457 data) were $>11.4 \mathrm{~m}$ within a 2-min span, a threshold of movement rate based on PSAT 131932, where all 6 putative spawning rise events had movement rates above this threshold, while no other time period had rates at or above that level (see Additional file 1). PSAT 131931 also had ascents $>11.4 \mathrm{~m}$ within the January and February ( $n=125$ events).

Additional file 3. Meta-analysis of published PSAT data sampling intervals. Frequency distributions of PSAT data sampling intervals for (a) $n=711$ PSAT tags analysed by Musyl et al. ([2]; data from their Table 3) and (b) $n=100$ published studies covering $>1000$ PSATs manufactured between 2000 and 2004 reported by Musyl et al. ([2]; data from their Table S2).

\section{Author details}

${ }^{1}$ Centre for Fisheries Ecosystems Research, Fisheries and Marine Institute, Memorial University of Newfoundland, PO Box 4920, St. John's, NL A1C 5R3, Canada. ${ }^{2}$ International Pacific Halibut Commission, PO Box 95009, Seattle, WA 98145, USA. ${ }^{3}$ Present Address: Canada Research Chair in Fisheries Ecology, Institut des Sciences de la mer de Rimouski (ISMER), Université du Québec à Rimouski, 310, allée des Ursulines, Rimouski, QC G5L 3A1, Canada.

\section{Acknowledgements}

This research was supported by Research and Development Corporation of Newfoundland and Labrador IgniteR\&D Grants to J.A.D.F. and D. R. We thank Captains L. Gaslard (Lady Terri) and R. Dobbin (J Elizabeth), their crews, and J. Spingle, for expert guidance at sea. H. Murphy and M. Castonguay facilitated tagging, while K. Krumsick and D. Kamada provided communications assistance during recoveries. J. Nielsen provided information on search strategies involving the goniometer. The technicians at Microwave Telemetry, Incorporated, gave helpful responses to all queries and rapid turnaround of archive and transmitted data series from $\mathrm{X}$-tags.

\section{Authors' contributions}

JADF, DR, and TL participated in the at-sea operations. JADF, DR and AL analysed, and interpreted the time series data. All authors contributed to writing, revising, and approving the final manuscript.

\section{Competing interests}

The authors declare that they have no competing interests.

\section{Availability of data and material}

The datasets used during the current study area available from the corresponding author on reasonable request.

\section{Consent for publication}

Not applicable.

\section{Ethics approval and consent to participate}

Tagging was undertaken under Fisheries and Oceans Canada Experimental License NL-2082-13 and Memorial University Animal Care Protocol 13-01-DR.

\section{Funding}

This research was supported by Research and Development Corporation of Newfoundland and Labrador IgniteR\&D grants to J.A.D.F. and D. R.

\section{Publisher's Note}

Springer Nature remains neutral with regard to jurisdictional claims in published maps and institutional affiliations.
Received: 3 November 2016 Accepted: 1 September 2017

Published online: 11 September 2017

\section{References}

1. Block BA, Jonsen ID, Jorgensen SJ, Winship AJ, Shaffer SA, Bograd SJ, Hazen EL, Foley DG, Breed GA, Harrison AL, Ganong JE, Swithenbank A, Castleton M, Dewar H, Mate BR, Shillinger GL, Schaefer KM, Benson SR, Weise MJ, Henry RW, Costa DP. Tracking apex marine predator movements in a dynamic ocean. Nature. 2011;475:86-90.

2. Musyl MK, Domeier ML, Nasby-Lucas N, Brill RW, McNaughton LM, Swimmer JY, Lutcavage MS, Wilson SG, Galuardi B, Liddle JB. Performance of pop-up satellite archival tags. Mar Ecol Prog Ser. 2011;433:1-28.

3. Braun CD, Kaplan MB, Horodysky AZ, Llopiz JK. Satellite telemetry reveals physical processes driving billfish behavior. Anim Biotelem. 2015;3:2.

4. Seitz AC, Norcross BL, Wilson D, Nielsen JL. Identifying spawning behavior in Pacific halibut, Hippoglossus stenolepis, using electronic tags. Env Biol Fishes. 2005;73:445-51.

5. Seitz AC, Loher T, Norcross BL, Nielsen JL. Dispersal and behavior of Pacific halibut Hippoglossus stenolepis in the Bering Sea and Aleutian Islands region. Aquat Biol. 2011;12:225-39.

6. Loher T, Seitz AC. Seasonal migration and environmental conditions of Pacific halibut Hippoglossus stenolepis, elucidated from pop-up archival transmitting (PAT) tags. Mar Ecol Prog Ser. 2006;317:259-71.

7. Loher T, Seitz AC. Characterization of active spawning season and depth for eastern Pacific halibut (Hippoglossus stenolepis), and evidence of probable skipped spawning. J NW Atl Fish Sci. 2008;41:23-36.

8. Peklova I, Hussey NE, Hedges KJ, Treble MA, Fisk AT. Depth and temperature preferences of the deepwater flatfish Greenland halibut Reinhardtius hippoglossoides in an Arctic marine ecosystem. Mar Ecol Prog Ser. 2012;467:193-205.

9. Armsworthy SL, Trzcinski MK, Campana SE. Movements, environmental associations, and presumed spawning locations of Atlantic halibut (Hippoglossus hippoglossus) in the northwest Atlantic determined using archival satellite pop-up tags. Mar Biol. 2014;161:645-56.

10. Seitz AC, Michalsen K, Nielsen JN, Evans MD. Evidence of fjord spawning by southern Norwegian Atlantic halibut (Hippoglossus hippoglossus). ICES J Mar Sci. 2014;71:1142-7.

11. Argos: worldwide tracking and environmental monitoring by satellite. www.argos-system.org. Accessed 15 Oct 2016.

12. Wilson SG, Stewart BS, Polovina JJ, Meekan MG, Stevens JD, Galuardi B. Accuracy and precision of archival tag data: a multiple-tagging study conducted on a whale shark (Rincodon typus) in the Indian Ocean. Fish Oceanogr. 2007;16:547-54.

13. Patterson TA, Hartmann K. Designing satellite tagging studies: estimating and optimizing data recovery. Fish Oceanogr. 2011;20:449-61.

14. Lutcavage ME, Lam CH, Galuardi B. Seventeen years and \$3 million dollars later: performance of PSAT tags deployed on Atlantic Bluefin and bigeye tuna SCRS/2014/178. Coll Vol Sci Pap ICCAT. 2015;71:1757-65.

15. Brunnschweeiler JM. Know your instruments: ensuring depth and temperature data from pop-up satellite archival tags are reported correctly. J Ecosyst Ecogr. 2014;54:004. doi:10.4172/2157-7625.54-004.

16. Breed GA, Costa DP, Goebel ME, Robinson PW. Electronic tracking tag programming is critical to data collection for behavioral time-series analysis. Ecosphere. 2011;2:1-12. doi:10.1890/ES10-00021.1.

17. Bauer RK, Forget F, Fromentin J-M. Optimizing PAT data transmission: assessing the accuracy of temperature summary data to estimate environmental conditions. Fish Oceanogr. 2015;24:533-9.

18. Albert OT, Lambert Y, Vollen T, Freitas C, Heggebakken L. Distinguishing pelagic and demersal swimming of deepwater flatfish by recording body angles. Am Fish Soc Symp. 2012;76:507-27.

19. Loher T. Analysis of match-mismatch between commercial fishing periods and spawning ecology of Pacific halibut (Hippoglossus stenolepis), based on winter surveys and behavioural data from electronic tags. ICES J Mar Sci. 2011;68:2240-51.

20. Lüke HD. The origins of the sampling theorem. IEEE Commun. 1999;April:106-8. 
21. Heffernan O, Righton D, Michalsen K. Use of data storage tags to quantify vertical movements of cod: effects on acoustic measures. ICES J Mar Sci. 2004;61:1062-70.

22. Rowcliffe JM, Carbone C, Kays R, Kranstauber B, Jansen PA. Bias in estimating animal travel distance: the effect of sampling frequency. Methods Ecol Evol. 2012;3:653-62.

23. Rosser G, Fletcher AG, Maini PK, Baker RE. The effects of sampling rate on observed statistics in a correlated random walk. J R Soc Interface. 2013;10:20130273. doi:10.1098/rsif.2013.0273.

24. Hoolihan JP, Luo J, Richardson DE, Snodgrass D, Orbesen ES, Prince ED. Vertical movement rate estimates for Atlantic istiophorid billfishes derived from high-resolution pop-up satellite archival data. Bull Mar Sci. 2009:84:257-64

25. Hoolihan JP, Luo J, Goodyear CP, Orbesen ES, Prince ED. Vertical habitat use of sailfish (Istiophorus platypterus) in the Atlantic and eastern Pacific, derived from pop-up satellite archival tag data. Fish Oceanogr. 2011;20:192-205.

26. Hoolihan JP, Luo J, Abascal FJ, Campana SE, De Metrio G, Dewar H, Domeier ML, Howey LA, Lutcavage ME, Musyl MK, Neilson JD, Orbesen ES, Prince ED, Rooker JR. Evaluating post-release behaviour modification in large pelagic fish deployed with pop-up satellite archival tags. ICES J Mar Sci. 2011;68:880-9.

27. Graves JE, Horodysky AZ, Latour RJ. Use of pop-up satellite archival tag technology to study post release survival of and habitat use by estuarine and coastal fishes: an application to striped bass (Morone saxatilis). Fish Bull. 2009;107:373-83.

28. Aranda G, Abascal FJ, Varela JL, Medina A. Spawning behaviour and postspawning migration patterns of Atlantic Bluefin Tuna (Thunnus thynnus) ascertained from satellite archival tags. PLoS ONE. 2013;8(10):e76445. doi:10.1371/journal.pone.0076445.

29. Finn RN, Østby GC, Norberg B, Fyhn HJ. In vivo hydration in Atlantic halibut (Hippoglossus hippoglossus); proteolytic liberation of free amino acids, and ion transport, are driving forces for osmotic water influx. J Exp Biol. 2002;205:211-24.

30. DFO (Fisheries and Oceans Canada). Stock assessment of Atlantic halibut of the Gulf of St. Lawrence (NAFO Divisions 4RST) for 2013 and 2014. Can Sci Advis Sec Sci Advis Rep. 2015;023:1-15.

31. DFO (Fisheries and Oceans Canada). Stock assessment of Atlantic halibut of the Gulf of St. Lawrence (NAFO Divisions 4RST) for 2011 and 2012. Can Sci Advis Sec Sci Advis Rep. 2013;033:1-20.

32. St-Pierre G. Spawning locations and season for Pacific halibut. In: IPHC scientific reports 70. International Pacific Halibut Commission, Seattle, WA, USA, 1984, pp. 1-46.

33. Galindo HM, Loher T, Hauser L. Genetic sex identification and the potential evolution of sex determination in Pacific halibut (Hippoglossus stenolepis). Mar Biotech. 2011:13(5):1027-37.

34. Loher T, Blood CA. Seasonal dispersion of Pacific halibut (Hippoglossus stenolepis) summering off British Columbia and the US Pacific Northwest evaluated via satellite archival tagging. Can J Fish Aquat Sci. 2009;66:1409-22.
35. Le Bris A, Fréchet A, Galbraith PS, Wroblewski JS. Evidence for alternative migratory behaviours in the northern Gulf of St Lawrence population of Atlantic cod (Gadus morhua L.). ICES J Mar Sci. 2013;70:793-804.

36. Le Bris A, Fisher JAD, Murphy HM, Galbraith PS, Castonguay M, Loher T, Robert D. Migration patterns and putative spawning habitats of Atlantic halibut (Hippoglossus hippoglossus) in the Gulf of St. Lawrence revealed by geolocation of pop-up satellite archival tags. ICES J Mar Sci. 2017;. doi:10.1093/icesjms/fsx098.

37. Loher T, Geernaert TO. Captive holding to develop long-term archival tagging protocols in Pacific halibut. IPHC Rep Assess Res Act. 2015;2014:469-73.

38. Galbraith PS, Chassé J, Nicot P, Caverhill C, Gilbert D, Pettigrew B, Lefaivre D, Brickman D, Devine L, Lafleur C. Physical oceanographic conditions in the Gulf of St. Lawrence in 2014. DFO Can Sci Advis Sec Res Doc. 2015;032:1-82.

39. Goodyear CP, Luo J, Prince ED, Hoolihan JP, Snodgrass D, Orbesen ES, Serafy JE. Vertical habitat use of Atlantic blue marlin Makaira nigricans: interaction with pelagic longline gear. Mar Ecol Prog Ser. 2008;365:233-45.

40. Scott JD, Courtney MB, Farrugia TJ, Nielsen JK, Seitz AC. An approach to describe depth-specific periodic behavior in Pacific halibut (Hippoglossus stenolepis). J Sea Res. 2016;107:6-13.

41. Neilson JD, Kearney JF, Perley P, Sampson H. Reproductive biology of Atlantic halibut (Hippoglossus hippoglossus) in Canadian waters. Can J Fish Aquat Sci. 1993;50:551-63.

42. Galbraith PS. Winter water masses in the Gulf of St. Lawrence. J Geophys Res. 2006;111:C06022. doi:10.1029/2005JC003159.

43. Martin-Robichaud DJ, Rommens M. Assessment of sex and evaluation of ovarian maturation of fish using ultrasonography. Aquac Res. 2001;32:113-20.

44. Loher T, Stephens SM. Use of veterinary ultrasound to identify sex and assess female maturity of Pacific halibut in nonspawning condition. N Am J Fish Man. 2011;31:1034-42.

45. Palaiokostas C, Bekaert M, Davie A, Cowan ME, Oral M, Taggart JB, Gharbi K, McAndrew BJ, Penman DJ, Migaud H. Mapping the sex determination locus in the Atlantic halibut (Hippoglossus hippoglossus) using RAD sequencing. BMC Genom. 2013;14:566.

46. Hussey NE, Kessel ST, Aarestrup K, Cooke SJ, Cowley PD, Frisk AT, Harcourt RG, Holland KN, Iverson SJ, Kocik JF, Mills Flemming JE, Whoriskey FG. Aquatic animal telemetry: a panoramic window into the underwater world. Science. 2015;348:1255642-1--10.

47. Wilmers CC, Nickel B, Bryce CM, Smith JA, Wheat RE, Yovovich V. The golden age of bio-logging: how animal borne sensors are advancing the frontiers of ecology. Ecology. 2015;96:1741-53.

\section{Submit your next manuscript to BioMed Central and we will help you at every step:}

- We accept pre-submission inquiries

- Our selector tool helps you to find the most relevant journal

- We provide round the clock customer support

- Convenient online submission

- Thorough peer review

- Inclusion in PubMed and all major indexing services

- Maximum visibility for your research

Submit your manuscript at www.biomedcentral.com/submit 